\title{
In Memoriam de Anacleto de Oliveira Faria
}

\author{
Tércio Sampaio Ferraz Jr. \\ Professor Titular de Introdução ao Estudo \\ do Direito da Faculdade de Direito da \\ Universidade de São Paulo.
}

\begin{abstract}
Estamos aqui reunidos para homenagear a memória de um professor desta casa. Quem fala em "memória" pensa imediatamente no passado, sentindo o fluxo dos anos como um tempo que ficou na esteira da história. Quem fala em "memória" desperta para a distância que separa os vivos dos mortos e imagina logo uma existência antiga, coroada dos sucessos normais dos que não passam apenas pela vida, mas vivem. Quem fala em "memória" percebe o pensamento estirar-se para bem longe e pretende estar diante de uma experiência acabada, que nasce num ponto qualquer e termina quando todos os caminhos já foram percorridos. No entanto, a memória que hoje reverenciamos não é a de um homem que viu completar-se diante de si o ciclo de uma existência. Pois é memória interrompida, atravessada pela morte em plena pujança da sua criatividade. Faleceu o professor Anacleto de Oliveira Faria aos 57 anos quando principiava apenas a dura tarefa de refletir sobre si mesmo, de arrancar de sua vida o sentido de sua própria existência e de propor afinal o projeto de sua posteridade.
\end{abstract}

Diziam os antig.os gregos que a vida é uma eterna repetição. O movimento das estações, o ciclo interminável das colheitas, o sol que levanta e se põe, lhes diziam que a existência natural e animal não passava desta volta completa, sem começo nem meio nem fim. Mas, ao contrário disto, incrustada em um cosmo em que todas as coisas eram eternamente cíclicas, era justamente a mortalidade que se tornava a marca distintiva da existência humana. Só os homens eram mortais. E nisto consistia a sua mortalidade: mover-se ao longo de uma linha retilínea em um universo onde tudo se movia em uma ordem cíclica. Sempre que os homens perseguem seus objetivos, lavram a terra rude, forçam nas velas o vento, cortam 
- mar encapelado, eles estão seccionando um movimento que é desprovido de objetivo e encerrado dentro de si. A morte é uma interrupção e, ao mesmo tempo, aquilo que possibilita um sentido à vida humana. Sem a morte somos apenas pó que ao pó retorna.

Pois é justamente porque o homem morre é que ele é também memória. A recordação o distingue da natureza física e dos animais. Na memória dos seus feitos e das suas ações, o homem mortal dá sentido a sua própria vida. Em toda filosofia verdadeiramente cristã, o homem é um "peregrino sobre a terra". Daí a importância dos eventos seculares, que devem ser guardados, por possuirem o caráter de exemplos, uma espécie de estalão no qual se mede a própria capacidade para a grandeza. Uma vida sem memória é como o ciclo das marés: não existe individualmente, não se distingue, sucumbindo no eterno vai e vem das águas.

Não faz 7 anos, Anacleto de Oliveira Faria despertava para a memória da sua própria existência. Num trabalho intitulado "Contribuição para as memórias acadêmicas", publicado na Revista da Faculdade de Direito, ele recordava. E ao fazê-lo, retirava da futilidade cíclica dos eventos de todos os dias, por exemplo, o traço humano e mortal "do famoso sino que tradicionalmente marcava - e marca ainda hoje - o início e o fim das aulas". Em 1939, tendo apenas 15 anos, lembrava-se ainda de ter sido obrigado a participar de uma grotesca procissão de "trote", todos os calouros em trajes menores, e que não se consumou pela chegada repentina do então Diretor da Escola, prof. Jorge Americano. Quantos de nós, antes e depois, não passamos igualmente por situações semelhantes! Afinal, na riqueza das suas tradições a velha Academia é um repertório de eventos simples que se repetem a cada geração, mas que a memória do homem mortal que somos perpetua e dá sentido.

Anacleto de Oliveira Faria faz parte de uma geração, a dos bacharelandos de 1945, que viveu, como ele mesmo refere, citando Charles Dickens, "o melhor dos tempos e o pior dos tempos". Assim, em 1941, recordava-se ele, algum espírito bajulador tivera a infeliz idéia de propor ao Conselho Universitário a outorga a Getúlio Vargas do título de Professor Honoris Causa da Universidade de São Paulo. Na manhã de 22 de setembro a Faculdade estava, por isso, em pé de guerra, a estátua de José Bonifácio coberta de crepe negro. Neste dia, e nos subseqüentes, grupos de alunos, com estandartes vermelhos da velha Academia, percorriam as ruas adjacentes à Faculdade, 
gritando "morras" ao ditador e clamando pela volta ao regime democrático. Fora decretada greve geral dos estudantes. E algum tempo depois, após um sério entrevero com o diretor, a Faculdade foi fechada, para reabrir-se 15 dias após, prosseguindo-se as atividades normais até o fim do ano letivo. Mas, recordava-se ele, "a vitória coube aos estudantes: o desarrazoado título de Professor "honoris causa" não concedido ao ditador".

A vida de sua geração foi, assim, marcada por um enfrentamento vigoroso, pelo desafio constante ao regime de 37 , por tradição de democracia, independência e liberdade, permanecendo irredutivelmente ligada aos ideais deste velho convento franciscano, picando, constantemente com o ferrão da rebeldia, o diorso da ditadura.

Quem olha, portanto, com olhos prospectivos para os traços marcantes de sua experiência pública nascente, não se espanta de vê-lo trilhar, posteriormente, as sendas de uma vida profissional e intelectual toda ela dominada por uma reflexão vigorosa sobre o sentido da experiência democrática como uma experiência de equilíbrio, e sobre o sentido do direito como uma experiência de justiça centrada na dignidade da pessoa humana.

Numa obra de 1958 intitulada "Democracia Humana", dizia Anacleto de Oliveira Faria que um regime democrático deve ser concebido como um triângulo que, por sua natureza mesma, possui três lados: o político, o econômico e o cultural. $\mathrm{E}$ como um triângulo tem de ter 3 lados ou não será um triângulo, assim também a democracia. O ângulo político da democracia traduz-se pela participação efetiva do povo na vida política, o que na prática ocorre por meio da representação popular enquanto um suporte necessário para evitar a todo transe qualquer forma de massificação desequilibradora - a tirania das massas - ou de individualismo exacerbado e excessivo - o descrédito das instituições em nome de uma pseudoliberdade de cunho anárquico. O ângulo econômico, por sua vez, representa uma garantia material incontornável, sem a qual a democracia política é uma ilusão. Verbera, neste sentido, o capitalismo enquanto regime fundado sobre a fecundidade do dinheiro, a idéia de lucro máximo e a concorrência desenfreada. Construir, dizia ele, a participação popular à custa da miséria das massas é mistificar a democracia autêntica. Se não damos a cada homem o direito e as condições de exercício da liberdade econômica, ou seja o direito de possuir e administrar, a democracia é uma farsa. Mas tudo isto será um 
triângulo de pé quebrado sem o aspecto cultural. Com uma intuição e uma percepção meticulosa, afirmava ele que mais do que qualquer regime, a democracia exige largas elites humanas em todas as classes sociais, mesmo porque, conforme Aristóteles, não deve igualar as posses, mas a educação humana, intelectual e moral dos cidadãos. Cultura, aqui, não é meio sinônimo de instrução, não significa apenas alfabetização em massa ou ensino para todos. Cultura é, antes de tudo, formação da consciência pelo exercício livre das mais dignas manifestações do ser humano enquanto recebe sua personalidade, seus direitos e seus deveres, conjugados com o respeito pelo próximo. Nestes termos, democracia é, antes de tudo, o oposto de um regime erigido sobre a propaganda cega e manipuladora e sobre a ferocidade dos tecnicismos cínicos perante a justiça.

Fundado neste tripé equilibrado e harmônico, Anacleto de Oliveira Faria verberava, então, o desencanto de uma democracia brasileira, com palavras que, escritas em 1958, parecem acompanhar tristemente a sina de nosso povo. Como conseguir a democracia, perguntava ele, se a cúpula dirigente da Nação - estruturada em grilhões políticos e econômicos - impede, por todos os meios, uma autêntica educação de massas; mantém, de forma intransigente uma legislação eleitoral falha; corrompe, de modo permanente, grande parte dos órgãos de difusão do pensamento; e seduz, pelo controle da quase totalidade desses mesmos órgãos, a massa popular, no sentido de lhe impedir um perfeito conhecimento dos problemas políticos da nação? E concluia, de uma forma profética: "enquanto não for rompido o círculo vicioso: lei falha - eleição de tubarões fantasiados de populistas - manutenção do statu quo, com a miséria cada vez maior do povo - sedução eleitoral desse mesmo povo semi-analfabeto, incapaz de vencer a pressão da propaganda - conseqüentemente reeleição dos endinheirados - enquanto não for rompido o círculo vicioso, a nossa democracia não passará de rótulo que esconde o domínio total da plutocracia viciosa e voraz". (41-42)

Palavras fortes e veementes. Não se leia, porém, na contundência um pensador apaixonado e arrebatado. Isto porque, acima de tudo, Anacleto de Oliveira Faria foi um jurista. E como homem do direito, soube cultivar com dedicação e pertinácia, a virtude máxima da prudência. Assim, sua concepção da democracia vasada, como todas as concepções, numa retórica aberta, se concretiza na talvez única forma possível de realizá-la: no valor da pessoa, cuja dignidade e direitos são para ele da esfera das coisas naturalmente sagradas. Foi, 
neste sentido, o personalismo a orientação filosófica que marcou o seu pensamento político e jurídico.

No centro de toda a sua reflexão está, assim, a pessoa, que é mais que um indivíduo, pois governando-se pela inteligência e pela vontade, não existe de modo físico, mas sobreexiste espiritualmente, constituindo, por si, um microcosmo. Em sua tese de doutoramento sobre "As alterações do contrato de locação de imóveis residenciais urbanos no direito brasileiro", apresentada em 1963 à cadeira de Instituição de Direito Privado da Faculdade de Ciências Econômicas e Administrativas da Universidade de São Paulo, o cerne de suas preocupações, para além das sistematizações dogmáticas que o tema exigia, era justamente o papel vivificador do personalismo no seio da ciência jurídica.

Ao contrário do jurista formalista, muitas vezes cego para as expressões humanas e sociais do direito, Anacleto de Oliveira Faria principiou sua dissertação com uma vigorosa reflexão sobre a crise do mundo moderno e o papel, dentro dela, da crise do direito. Mostrava, com isso, o pensador preocupado com as ilusões da ordem e da harmonia que o simples estudo formal do direito costuma oferecer. Afinal, num mundo acossado por duas guerras totais em menos de 50 anos, que se transforma agilmente pondo por terra situações que pareciam estratificadas e que as substitui vãmente por uma crença balofa num vazio desenvolvimento científico e tecnológico, nenhum trabalho sobre o direito poderia, a seu ver, deixar de lado uma indagação sobre o sentido das estruturas da ordem jurídica.

$\mathrm{E}$ foi assim que, disposto a enfrentar o problema, sustentou em sua dissertação a necessidade de se enfatizar com rigor de pensamento e coragem de ação que o direito deve estar a serviço da pessoa, não de um indivíduo detentor de bens e de poder, mas de um ser independente e livre que é um todo numa sociedade de todos. Pois, se o direito em crise num mundo em crise é um direito amarrado ao individualismo formal e abstrato dos códigos, o seu antídoto só pode ser um direito rehumanizado. Assim, contra o direito do domínio individualista, que atrela a propriedade ao uso despreocupado do interesse público e de terceiros, mas confia também o direito do pseudo-antidomínio socialista, que atrela a liberação do homem à eliminação da propriedade, o personalismo jurídico, a seu ver, vai fundar todos os direitos nesta forma suprema e radical de domínio que é o domínio de si mesmo, em uma palavra, no ser-livre. E como o ser-livre é a própria essência da natureza humana, segue-se que só na liberdade a proprie- 
dade tem sentido, só na generalização da propriedade a liberdade tem um fim. E aqui está o seu instrumento concretizador da democracia de que falávamos há pouco. Pois, como disse então Anacleto de Oliveira Faria, "não se pode falar em autêntica democracia, num regime de homens livres se, ao aspecto político do mesmo, não corresponder o aspecto econômico: a democracia política deverá ser completada pela democracia econômica que se caracterizaria, principalmente, pela distribuição mais equânime dos bens do universo" Equanimidade esta que deve estar adstrita a um critério de prudência e razoabilidade, pois, dizia ele citando Rénard, "a propriedade humana não implica senão na quantidade de riquezas necessárias às exigências da vida e para as quais essas riquezas foram criadas".

Eis porque, ponderava ele em sua dissertação, concluindo agora sobre as repercussões do personalismo sobre o direito em crise num mundo em crise, o direito do milionário ao seu segundo milhão não é absolutamente da mesma espécie que o do operário a alguma participação nos lucros, na gerência ou propriedade da indústria em que trabalha; eis porque também o direito de um homem possuir um iate não é um direito tão primário como o do salário mínimo; eis porque o direito do cidadão a uma casa decente para habitar não é igual ao direito do capitalista que detém dezenas de casas para viver de suas rendas.

Palavras de rigor e de coragem, escritas há 18 anos, mas que sobrevivem ao seu autor e lhe conferem o projeto da sua própria posteridade. O projeto de uma vida que, em sendo crítico perante a sociedade em que viveu, soube exercitar a sua crítica dentro dela, buscando a sua transformação com os instrumentos que ela própria fornecia. Por isso uma crítica menos utópica do que a daqueles que, a pretexto de transformar só querem eliminar, cerrando, muitas vezes, o próprio galho em que estão sentados. Quem conheceu, portanto, Anacleto de Oliveira Faria, sabe que sua reflexão jurídica, política e filosófica não poderia ter tido outro tema senão o direito civil cuja perenidade ele procurou arrancar das elocubrações pessimistas dos que apontam na sua publicização o sinal da sua decadência, objeto de sua tese de livre docência de 1965. Como não poderia ter tido outro tema que o princípio da igualdade jurídica que ele analisou em seu concurso para a cátedra de Instituições de Direito, com o fito de identificar as distorções que o transformam, tantas vezes, em impostura. Em ambos os temas, o mesmo espírito veemente, sem deixar de ser razoável; o mesmo crítico agudo sem pretender ser demolidor; o mesmo 
pensador rigoroso, sem deixar de ter uma abertura para a experiência viva; o mesmo jurista adstrito à scientia juris, sem ignorar a dignidade maior da prudentia juris; o mesmo homem inquieto e desafiador, sem deixar de ser um homem centrado e tranquilizado nas suas próprias convicções.

Este homem não está mais hoje entre nós. Atravessou sua existência que foi, provavelmente, como ele mesmo afirmou de sua vida estudantil "o melhor dos tempos e o pior dos tempos". Iniciou sua experiência acadêmica num período de desencanto e desolação. Exerceu sua profissão e seu magistério pregando uma política de harmonia e de justiça. No quadro de formatura de sua turma de 1945 estão inscritos os seguintes versos d'A Divina Comédia: per quel cammino acoso, entramo a ritornar nel chiaro mondo .. e quindi uscimo a riveder le stelle". Em verdade, tais versos aplicam-se de modo rigoroso não só à sua sofrida geração universitária. Revelam-se, neste momento, o sinal profético da vida de um homem que, na medida de suas forças, concorreu sempre para que se pudesse sair das trevas e para o qual a morte súbita, antes da existência, coroada, o fez voltar a "riveder le stelle".

\section{Carta de Agradecimento da Família De Oliveira Faria}

Agradecendo a homenagem prestada pela Congregação ao Professor Dr. Anacleto de Oliveira Faria, nosso professor-assistente do Departamento de Filosofia do Direito Dr. José Eduardo Campos de Oliveira Faria, filho do homenageado, remeteu ao Sr. Diretor uma carta de agradecimento que se transcreve a seguir:

São Paulo, 13 de maio de 1981

Exmo. Sr. Professor Doutor Antonio Chaves

DD. Diretor da Faculdade de Direito da Universidade de São Paulo

Senhor professor,

A família de Anacleto de Oliveira Faria incumbiu-me, na qualidade de filho mais velho e de professor-assistente desta instituição universitária, de transmitir a V. Exa. e a todo o corpo docente os agradecimentos pela honrosa homenagem prestada nesta data.

Evidentemente, esta é uma responsabilidade ingrata. Pois, em sua essência, esta solenidade nada mais é do que a cristalização de uma ausência. Estamos reunidos, porque estamos sós. A solidião, disse Octavio Paz, "consiste num aspirar a realizar-se em outro". Se as palavras deste poeta mexicano 
tiverem :para nós algum significado, esta nossa tentativa de "realização" na memória de Anacleto de Oliveira Faria não deve ser interpretada como reverência a um morto, mas com a lembrança viva de quem sempre perseverou na realização com o próximo.

Essa busca incessante de comunhão foi, em vida, sua palavra de ordem enquanto chefe de família, jornalista, advogado $e$, principalmente, professor universitário. Uma palavra de ordem que o levou, sem hesitação e às vezes com uma carinhosa aspereza, a conciliar, a seu modo, pensamento e praxis em todios os minutos de sua vida. Tinha consciência - disse-o a mim quando fui indicado para as atividades docentes no Departamento do qual mais tarde ele viria a ser chefe - de que as ações, a vida e o trabalho somente teriam sentido desde que voltados a uma explicita defesa do homem.

Animavam-no, nas recomendações a um filho recém-formado que julgava anti-ortodoxo para uma carreira no mundo jurídico, as palavras do padre Vieira no clássico Sermão da Sexagésima (do qual sempre se valeu para formalizar seus pedidos de pai): "uma coisa é o semeador, e outra o que semeia; uma coisa é o pregador, e outra o que prega. O semeador é nome; o que semeia e o que prega é ação; $e$ as ações são as que dão o ser ao pregador".

Anacleto de Oliveira Faria semeou e pregou desde o momento em que se formou, nesta escola, em 1945, até o dia de sua morte. Foi, antes e acima de tudo, um professor universitário. No desempenho de seu papel, estava ciente da lacuna entre a geracão de seus velhos mestres - ele que a conhecera por intermédio de Sebastião Soares de Faria - e as aspiraçóes libertárias das novas gerações - ele que também as conhecera em casa, por meio de seus cinco filhos, dois dos quais deixou nesta Academia.

Nunca aceitou valores esclerosados. Mas também jamais se impressionou com a anti-ortodoxia. Homem que a 2. ${ }^{a}$ Guerra tirou dos bancos acadêmicos para levá-lo a uma tropa que viveu a angústia de uma batalha que nunca combateu, universitário que também encontrou na luta contra o Estado Novo seu moinho de vento e católico que viveu todas as contradições de uma ambigua democracia cristã, converteu frustração por frustração na matéria-prima da compreensão da crise de seu tempo - temática, aliás, sempre presente em suas palavras e em seus textos, onde a preocupação com o individualismo e personalismo jurídicos revelam seu temor com o risco de desaparecimento da identidade individual no mundo contemporâneo. 
Foi com essa argamassa que construiu sua carreira e amealhou a respeitabilidade dos filhos - independentemente das divergências ideológicas inevitáveis. À inquietude destes, respondia que passado e tradição não eram a mesma coisa, convencido de que não se podia perder a dimensão de profundidade na existência e na experiência humanas, sob pena da própria perversão do homem livre. Explicando que a educação não poderia perder o sentido do passado, indagou-me certa vez: como ser iconoclasta num mundo muito mais antigo do que os seus 20 anos?

Em suma: semeador e pregador, enquanto professor preocupado em unir pensamento e ação na formação dias novas gerações, ao morrer, Anacleto de Oliveira Faria era um homem tranqüilo. Estava consciente e convicto, de um lado, do seu papel presente de mediador entre o velho e o novo; e, de outro, do refluxo da liberdade num contexto autocrático. Por isso mesmo, via seu trabalho universitário sob uma lógica peculiar, abrindo um terreno no qual não caminharia: a renovação docente do Departamento de Filosofia e Teoria Geral do Direito sem risco de solução de continuidade entre o trabalho deixado por dois amigos, os professores Goffredo e Reale, e o futuro.

$E$, preocupado com essa tarefa, numa de suas anotações no verso de uma das atas da congregação, no ano passado, anotou - mais uma vez - as palavras do padre Vieira: "palavras sem obras, são tiro sem bala: atroam, mas não ferem".

Portanto, esta homenagem, à qual toda a família agradece, tem para ela o significado cristalino e formal de que nosso pai realizou o que se propôs - de que viveu para a universidade, de que exerceu uma vita activa, enfim, de que pensou e agiu, construindo um nome que não é apenas motivo de nosso orgulho pessoal, mas fonte de energia - em especial para os dois filhos que deixou nesta Faculdade.

Apresentando a V. Exa. os protestos de elevada estima $e$ distinta consideração, pedindo que nossos agradecimentos sejam estensivos a todo o corpo docente,

Atenciosamente,

José Eduardo Campos de Oliveira Faria Professor-assistente 